\title{
Minimization for current peak-to-peak value in switched reluctance motor
}

\author{
Chaoyi Shang ${ }^{1}$, Aide $\mathrm{Xu}^{2, *}$, Qianni $\mathrm{Li}^{2}$, and Lepeng Huang ${ }^{1}$ \\ ${ }^{1}$ College of Electrical Engineering of Ships, Dalian Maritime University, 116026 Dalian, China \\ ${ }^{2}$ College of Information and Science Technology, Dalian Maritime University, 116026 Dalian, China
}

\begin{abstract}
For switched reluctance motor (SRM), due to the excessive peak-to-peak current occurs at the initial stage under the direct instantaneous torque control (DITC) algorithm, the motor efficiency has been affected to some extent. For this propose, a DITC optimization algorithm combined with high torque per ampere (HTPA) is introduced in this paper. Based on the traditional maximum torque-to-current ratio (MTPA) principle, the changing points of the inductance slope can be calculated. These points are also refer to the maximum torque-to-current ratio. Taking these points as the basis for sector division of the mechanical angle of each phase, the operation rule is optimized in the newly divided interval to select the corresponding voltage vector. The optimal voltage vector is obtained by the method of segmented variable duty cycle modulation. The new algorithm was validated on a three-phase $12 / 8$ switched reluctance motor. Compared to conventional DITC, HTPA-DITC reduces peak current evidently. At the same time, the threephase stator current is reduced under the same load conditions, thereby increasing the torque-to-current ratio of the motor.
\end{abstract}

\section{Introduction}

Switched reluctance motor (SRM) is a new type of variable speed motor. Compared with asynchronous motor and permanent magnet synchronous motor (PMSM), it has a series of advantages, such as simple structure, low cost, reliable power circuit, and high efficiency. However, due to the double salient structure of the body and the high non-linearity of the electromagnetic relationship, there are several difficulties in efficiency maximization and current value minimization under the constant torque [1].

As one of the field-weakening control methods, maximum torque per ampere (MTPA) has been used to optimize the efficiency of traditional motors. MTPA control strategy can generate the minimum current corresponding to the given torque, for the optimal scheme of torque per ampere (TPA).

Based on the rotating coordinate system and current vector control, the MTPA control for PMSM is proposed in [2]. As a new decoupling controller, MTPA has always been developed on current optimization [3-4] and loss analysis by researchers. Literature [5] proposes a prediction control based on pulse width modulation (PWM) and MTPA current optimization. Literature [6] analyzes the loss under different field-weakening controls based on the deadbeat prediction scheme in detail. Among them, the performance of MTPA is better than other field-weakening control, such as maximum torque per voltage control.
Due to the advantages of the structure and working principle of PMSM, both the rotor and accurate torque expressions are accurate. However SRM is not qualified to construct rotating coordinate system because of the loss rotor flux. In addition, the high non-linearity of SRM will increase complexity, especially the current decoupling control, the application of traditional MTPA in SRM is limited. In order to solve these issues, adopting high torque per ampere (HTPA) to analyze the relationship between torque and current is practical. HTPA is based on the idea of MTPA to find the maximum points of TPA corresponding to different torques for SRM. These points are also the maximum torque -current ratio under the given torque. The ideal of HTPA can be introduced into smooth torque control as a current optimization module.

As an effective method to solve SRM smooth torque control, direct instantaneous torque control (DITC) formulates different hysteresis control rules for singlephase operation region and overlap region of two-phase simultaneous operation according to real-time rotor position, and directly selects switch vector output to power converter through hysteresis control rules. The hysteresis control rule directly selects the switch vector output to the power converter [7-8]. However, DITC requires complex operation rules to generate smooth torque in the overlap region, the current peak is too high in the initial stage of current rise so does the torque. This performance leads to the lower value of TPA. This phenomenon can lead to excessive peak-to-peak current and low motor efficiency.

\footnotetext{
* Corresponding author: aidexu@dlmu.edu.cn
} 
For the excessive peak-to-peak current value at the initial stage caused by DITC algorithm of SRM, a new current optimization scheme of DITC combined with HTPA control strategy is proposed, that is HTPA-DITC. Through the ideal of HTPA, the largest torque-current ratio point in one electrical cycle can be obtained. In addition, the mechanical angle corresponding to the point can also be obtained. Using the special mechanical angle and piecewise variable duty cycle modulation, overlap region of DITC is sector-divided and operation rule is optimized as well. The optimization control strategy is verified in simulation and experiment.

\section{Principle of the proposed HTPA}

\subsection{Torque calculation of switched reluctance motor}

According to kirchhoff's voltage law, the single-phase instantaneous voltage of SRM is expressed as

$$
U_{k}=i_{k} R+\frac{d \psi_{k}}{d t}=i_{k} R+\frac{\partial \psi_{k}\left(\theta, i_{k}\right)}{\partial i_{k}} \cdot \frac{d i_{k}}{d t}+\frac{\partial \psi_{k}\left(\theta, i_{k}\right)}{\partial \theta} \cdot \frac{d \theta}{d t}
$$

In the formula, $k$ represents phase number, $k=1,2,3$, $U_{k}$ represents phase voltage, $i_{k}$ represents phase current, $R$ represents the winding impedance of the motor, $\psi_{k}\left(\theta, i_{k}\right)$ represents phase flux linkage.

In SRM, torque is usually calculated according to the magnetic common energy, and the general formula is shown as follows

$$
T_{k}=\frac{\partial}{\partial \theta} W^{\prime}\left(\theta, i_{k}\right) \mid i_{k}=\text { const }
$$

Where $W^{\prime}\left(\theta, i_{k}\right)$ represents the magnetic co-energy, which is expressed by equation (3)

$$
W^{\prime}\left(\theta, i_{k}\right)=\int_{0}^{i_{k}} \psi_{k}\left(\theta, i_{k}\right) d i_{k}=\int_{0}^{i_{k}} L_{k}\left(\theta, i_{k}\right) i_{k} d i_{k}
$$

Formula (3) shows that the magnetic common energy is a function of position Angle and phase current, $L_{k}\left(\theta, i_{k}\right) \quad$ is the phase inductance. When the magnetic saturation effect is ignored, $L_{k}\left(\theta, i_{k}\right)$ can be reduced to a function independent of phase current $L_{k}(\theta)$. In the linear inductance model, the phase torque and composite torque can be expressed as equations (4) and (5):

$$
\begin{aligned}
& T_{k}=\frac{1}{2} i_{k}{ }^{2} \frac{d L_{k}(\theta)}{d \theta} \\
& T_{\text {total }}=\sum_{k=1}^{3} T_{k}\left(\theta, i_{k}\right)
\end{aligned}
$$

Captions should be typed in 9-point Times. They should be centred above the tables and flush left beneath the figures.

\subsection{Analysis of HTPA point}

When the winding pressure drop is ignored, formula (1) can be rewritten as

$$
U_{k}=L_{k} \frac{d i_{k}}{d t}+i_{k} \frac{d L_{k}}{d t}=L_{k} \frac{d i_{k}}{d t}+i_{k} \frac{d L_{k}}{d \theta} \omega_{r}
$$

From (6), (7) is available

$$
\frac{U_{k}}{\omega_{r}}=L_{k} \frac{d i_{k}}{d \theta}+i_{k} \frac{d L_{k}}{d \theta}
$$

where $\omega_{r}$ is rotor speed, in the linear inductance model, The change of inductance slope is called $\theta_{1 u}$. From the opening angle $\theta_{o n}$ to $\theta_{1 u}$, inductance is remained constant as $L=L_{\text {min }}, i\left(\theta_{\text {on }}\right)=0$ then

$$
i_{k}(\theta)=\frac{U_{k}}{L_{\min }} \cdot \frac{\theta-\theta_{o n}}{\omega_{r}}
$$

The rate of current change is

$$
\frac{d i_{k}(\theta)}{d \theta}=\frac{U_{k}}{\omega_{r} L_{\min }}
$$

According to equations (8) and (9), the current reaches its maximum at $\theta_{1 u}$, and the rate of current changing is inversely proportional to the speed. When the speed rises, the phase current change rate decreases, and the current tracking ability decreases [9]. As the load is increased, in order to provide sufficient torque, the peak current value has to increase to obtain a sufficiently large current.

To solve the problem of excessive peak-to-peak current, the torque-current relationship can be established based on the ideal of HTPA. HTPA means the torque ratio generated by stator phase current reaches the maximum value. Under the constant output torque situation, if the motor consumes less stator current, the efficiency of the motor can be improved.

The average torque of an electric period, root mean square value of current and the definition of TPA can be expressed by equation (10), (11), (12) respectively:

$$
\begin{gathered}
T_{a v}=\frac{\int_{0}^{\frac{2 \pi}{N_{r}}} \frac{1}{2} i_{k}{ }^{2} \frac{d L_{k}(\theta)}{d \theta} d \theta}{2 \pi / N_{r}} \\
I_{r m s}==\sqrt{\frac{\int_{0}^{\frac{2 \pi}{N_{r}}} i_{k}^{2} d \theta}{2 \pi / N_{r}}} \\
\mu=\frac{T_{a v}}{I_{r m s}}=\sqrt{\frac{N_{r}}{8 \pi}} \frac{\int_{0}^{\frac{2 \pi}{N_{r}}} i_{k}^{2} \frac{d L_{k}(\theta)}{d \theta} d \theta}{\sqrt{\int_{0}^{\frac{2 \pi}{N_{r}}} i_{k}{ }^{2} d \theta}}
\end{gathered}
$$

$N_{r}$ is the logarithm of rotor poles. In the inductance linear region, $d L_{k}(\theta) / d \theta$ is a constant value, and the inductance slope in the nonlinear region is zero. From equations (9) and (12), $\theta_{1 u}$ is the point with the maximum torque current ratio. 


\section{Implementation of HTPA-DITC}

\subsection{Re-division the sectors}

Although $\theta_{1 u}$ is the point with the maximum torque current ratio, it can also be called as critical overlap. The inductance is very small before this point, the current rises very quickly, then the inductance enters the linear region, the slope of the inductance is the largest, and the current is quickly consumed. As the large TPA represents less copper consumption, to a certain extent, it means higher efficiency. In this paper, the mechanical angle of each phase is divided into five regions with $\theta_{1 u}$ as the dividing point and the nonlinear inductance model, as shown in figure 1 . Taking phase $\mathrm{A}$ as an example, $\mathrm{A}_{\text {on }}$ is the opening angle, $A_{\text {off }}$ is the relevant breaking Angle, and $A_{1 u}$ is the change point of inductance slope of phase A.

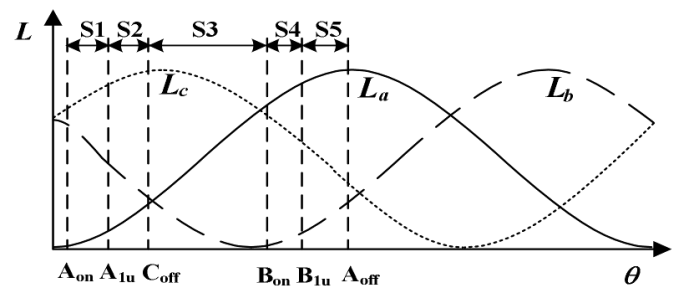

Fig.1. Re-division the sectors

\subsection{Operation rule of HTPA-DITC}

If the three-phase winding working order of SRM is $\mathrm{C} \rightarrow \mathrm{A} \rightarrow \mathrm{B} \rightarrow \mathrm{C}$, hysteresis band is . Different and variable duty cycles are applied to the overlapping region and single-phase conducting region respectively. Among them, the phase A can be taken as an example:

S1: Phase A acts as the excitation phase. When $\mathrm{A}$ is turned on, the inductance of phase $\mathrm{A}$ is small, the rate of change of inductance is almost zero, and the torque that can be supplied is small. In this region, the torque is mainly supplied by phase $\mathrm{C}$. When the torque error is less than the lower bound of the hysteresis loop, $\Delta T \leq-T_{H}$, switch off A-phase. When the torque error is larger than the upper limit, turn it on.

S2: At this time, the A-phase inductance is still small, but the inductance change rate is increasing, and the torque variation in this sector is relatively severe. Before the $\mathrm{C}$ phase switch off, the torque still needs to be provided by $\mathrm{C}$ phase. When the error is within the torque hysteresis and over zero, phase A should under the freewheeling state.

S3: The sector is a single-phase operation region. When the torque error is over zero, the phase A is turned on, and the duty ratio is determined according to the duty ratio formula. When the torque error is less than zero, phase A continues to flow. In this sector phase $\mathrm{C}$ is completely shut down.

S4: At this time, the A phase will be transformed into the demagnetization phase, and phase $\mathrm{B}$ will face the same situation when it is just turned on. The torque is mainly provided by phase $\mathrm{A}$.

S5: Before phase A is completely turned off and the torque of phase B has not been established yet, it is still necessary to excite Phase A. After the torque of phase B is established, the phase $\mathrm{A}$ is brought into the freewheeling state, and after the turn-off angle, the back pressure is applied.

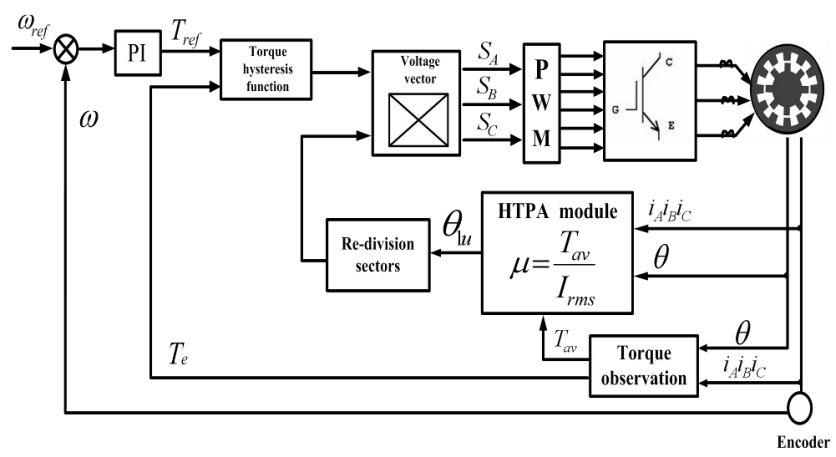

Fig.2 Control block diagram of HTPA-DITC

\section{Simulation analysis}

In this paper, the DITC and HTPA-DITC are simulated and verified in MATLAB from a three-phase 12/8-pole SRM. At the same turn-on turn-off angle, $650 \mathrm{rpm}, 5$ $\mathrm{N} \cdot \mathrm{m}$, the comparison of HTPA-DITC and DITC is shown in figure 3 . In addition, $1000 \mathrm{rpm}, 5 \mathrm{~N} \cdot \mathrm{m}$, the comparison of HTPA-DITC and DITC is shown in figure 4 .
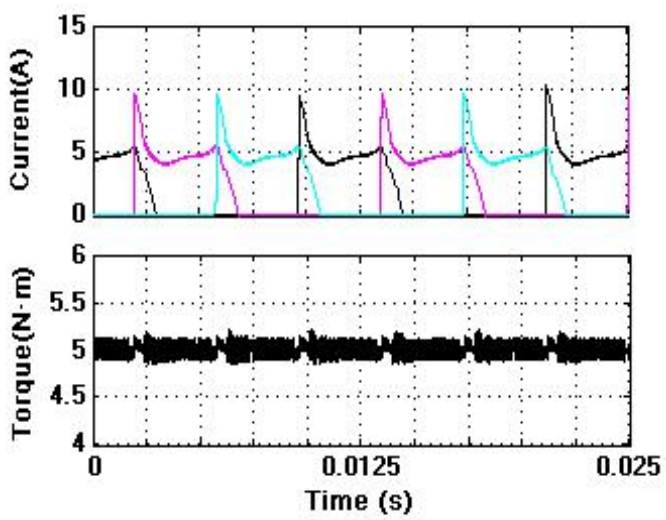

(a)
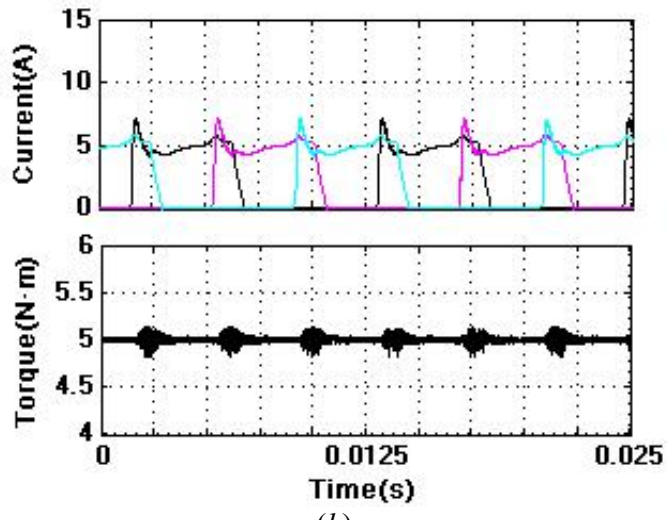

(b)

Fig.3 Simulation waveform of DITC and HTPA-DITC with $650 \mathrm{rpm}, 5 \mathrm{~N} \cdot \mathrm{m}(a) \operatorname{DITC}(b) \mathrm{HTPA}-\mathrm{DITC}$ 

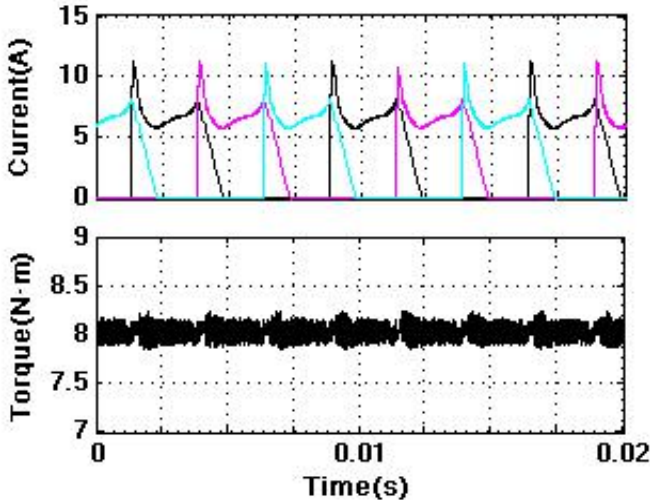

(a)
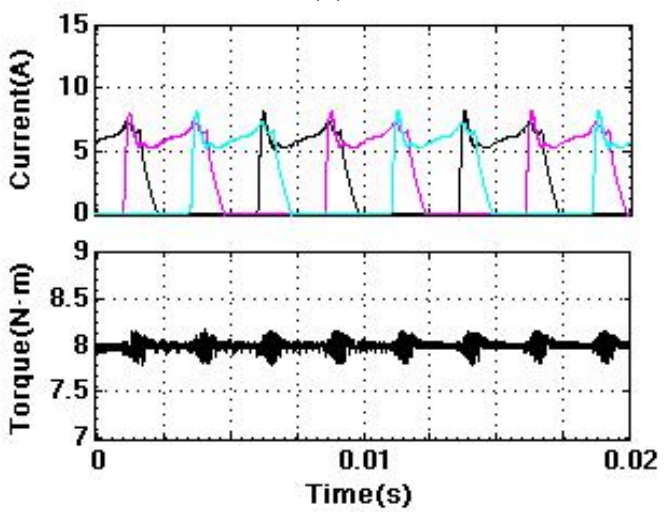

(b)

Fig.4 Simulation waveform of DITC and HTPA-DITC with $1000 \mathrm{rpm}, 8 \mathrm{~N} \cdot \mathrm{m}(a)$ DITC $(b)$ HTPA-DITC

As can be seen from figure 3 and figure 4, by HTPA control and segmenting the duty cycle modulation, the voltage vector is applied to the re-divided sectors, which can effectively reduce the current peak value about $2.1 \mathrm{~A}$ and 3.7A. Figure 5 is a comparison of the flux linkage of DITC and HTPA-DITC. the DITC algorithm's flux diagram is a three-leaf shape, while the optimized DITC flux is more even at the tip of the blade.

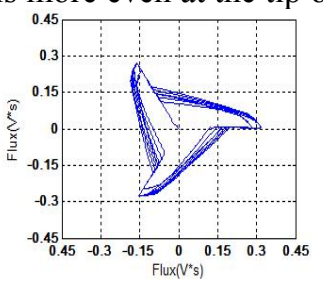

(a)

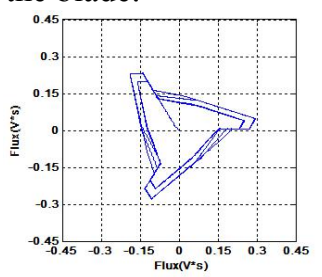

(b)
Fig.5 Flux-linkage circle of DITC and HTPA-DITC $(a)$ DITC (b)HTPA-DITC

Figure 6 shows TPA line chart and current peak value of DITC and HTPA-DITC under different loads and the different speeds.

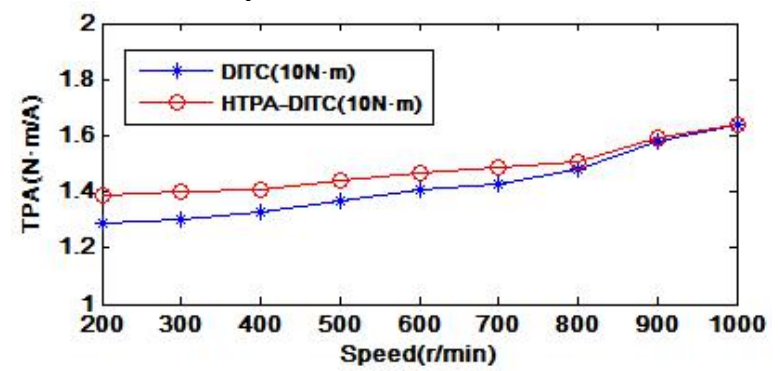

(a)

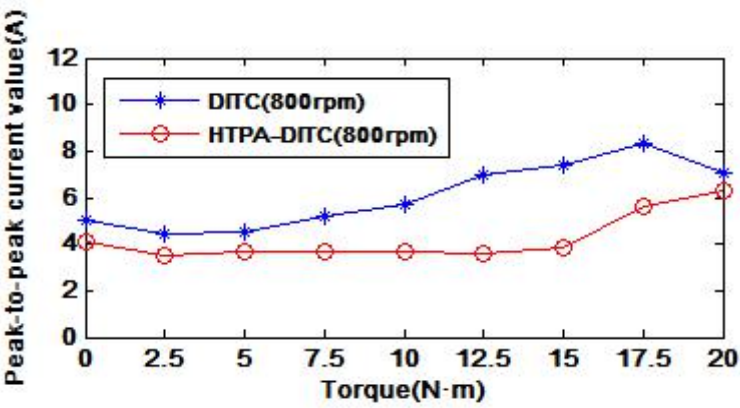

(b)

Fig.6. Comparison of DITC and HTPA-DITC with different situations $(a)$ DITC $(b)$ HTPA-DITC

According to figure 5, the DITC algorithm's flux diagram is a three-leaf shape, while the optimized DITC flux is more even at the tip of the blade. It can be seen from figure. 6 that the torque current ratio of HTPADITC is higher than DITC in a large range, and the peakto-peak current value of HTPA-DITC is lower than DITC, especially to the medium speed with light loading.

\section{Conclusion}

This paper points out many problems in traditional DITC, such as high peak-to-peak current and low torque-tocurrent ratio at the early stage of current rising. By combining the ideal of MTPA, the points of HTPA can be obtained. These points make the interval of HTPADITC redivide and conduction rule change. HTPA-DITC also optimizes the conduction rule, and modulates the optimal voltage vector by using the segmentation variable duty ratio. Therefore, PWM-DITC not only improves the current waveform, but also reduces the peak-to-peak current value, and further optimizes the torque-to-current ratio.

This work is supported by: Special Innovation Projects for the Double-First Class Construction under grant no.CXXM2019SS005, Dalian Science Technology Innovation Fund Project under grant no.2018J12GX039 and National Natural Science Foundation of China under grant no.51407021.

\section{References}

1. 1.A. Xu, C. Shang, J. Chen, J. Zhu and L. Han, A New Control Method Based on DTC and MPC to Reduce Torque Ripple in SRM. IEEE Access, 7, 68584-68593(2019).

2. S. Morimoto, M. Sanada and Y. Takeda, Widespeed operation of interior permanent magnet synchronous motors with high-performance current regulator. IEEE Tran on Industry Applications, 30, 920-926(1994).

3. T. Inoue, Y. Inoue, S. Morimoto and M. Sanada, Maximum Torque Per Ampere Control of a Direct Torque-Controlled PMSM in a Stator Flux Linkage Synchronous Frame. IEEE Trans on Industry Applications, 52, 2360-2367(2016). 
4. K. Li and Y. Wang, Maximum Torque Per Ampere (MTPA) Control for IPMSM Drives Based on a Variable-Equivalent-Parameter MTPA Control Law. IEEE Trans on Power Electronics, 34, 70927102(2019).

5. R. S. Dastjerdi, M. A. Abbasian, H. Saghafi and M. H. Vafaie, Performance Improvement of PermanentMagnet Synchronous Motor Using a New DeadbeatDirect Current Controller. IEEE Trans on Power Electronics, 34, 3530-3543(2019).

6. M. Saur, F. Ramos, A. Perez, D. Gerling and R. D. Lorenz, Implementation of deadbeat-direct torque and flux control for synchronous reluctance machines to minimize loss each switching period. APEC, 215-220(2016).
7. C. Shang, A. Xu, L.Huang and J. Chen, Flux linkage optimization for direct torque control of switched reluctance motor based on model predictive control. IEEJ Tran on Electrical and Electronic Engineering, 14,1105-1113(2019).

8. Zhu Yesheng, Zhang Guobao, Huang Yongming. PWM -Based direct Instantaneous torque control of switched reluctance Machine. Trans of China Elect Society,32, 31-39(2017).

9. YE J, BILGIN B, EMADI A. An extended-speed low-ripple torque control of switched reluctance motor drives. IEEE Trans on Power Electronics, 30, 1457-1470(2015). 